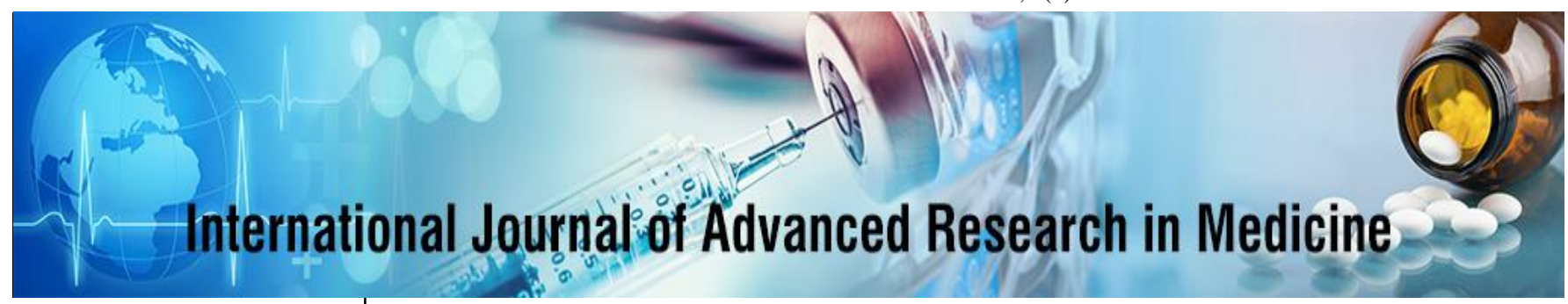

E-ISSN: 2706-9575

P-ISSN: 2706-9567

IJARM 2020; 2(2): 183-187

http://www.medicinepaper.net

Received: 19-05-2020

Accepted: 21-06-2020

Abdulameer Wadi Lafta

Ministry of Health, Baghdad

Al-Russafa Health

Directorate, Imam Ali

Hospital, Baghdad, Iraq

Farhan Hansah Aggar

Ministry of Health, Baghdad

Al-Russafa Health

Directorate, Imam Ali

Hospital, Baghdad, Iraq

Khaleel Salim Sayed

Ministry of Health, Baghdad

Al-Russafa Health

Directorate, Imam Ali

Hospital, Baghdad, Iraq
Corresponding Author:

Abdulameer Wadi Lafta

Ministry of Health, Baghdad

Al-Russafa Health

Directorate, Imam Ali

Hospital, Baghdad, Iraq

\section{Optimization of fluid therapy in elective abdominal surgery}

\author{
Abdulameer Wadi Lafta, Farhan Hansah Aggar and Khaleel Salim \\ Sayed
}

DOI: https://doi.org/10.22271/27069567.2020.v2.i2c.67

\section{Abstract}

The aim of the study was to assess the effect of intraoperative targeted infusion therapy, controlled based on monitoring stroke volume variability, on the postoperative results of major surgical interventions on the organs of the gastrointestinal tract.

Materials and Methods: The prospective study included 80 patients who underwent elective surgical interventions on the abdominal organs with the formation of an internecinal anastomosis. In the study group $(\mathrm{n}=41)$, infusion therapy was performed according to the developed protocol of targeted therapy, the key parameter of which was stroke volume variability. In the control group $(n=43)$, infusion therapy was performed based on the data of routine monitoring of hemodynamics (mean arterial pressure, heart rate, degree of blood loss, taking into account the intraoperative situation). In both groups, surgery was performed under identical conditions (combined anesthesia, identical drugs for induction and maintenance of anesthesia), the difference was in the approach to infusion therapy.

Results: In the study group, in comparison with the control group, the intraoperative volume of infusion was less, the number of patients with complications and the total number of complications were significantly lower, and the restoration of the functions of the gastrointestinal tract occurred earlier.

Conclusion: Targeted infusion therapy, based on monitoring stroke volume variability as a key parameter, allows optimizing the infusion load and contributes to a decrease in the number of patients with complications, as well as earlier restoration of gastrointestinal tract functions after major surgical abdominal interventions.

Keywords: Targeted infusion therapy, stroke volume variability (VVO), functional hemodynamic parameters, hypovolemia, hypervolemia, oxygen delivery

\section{Introduction}

The modern approach to infusion therapy, both in the perioperative period and in critical conditions, requires a justified prescription of infusion media (similar to drugs). It is necessary to take into account many factors - indications and possible contraindications, patient characteristics, the nature of the underlying and concomitant pathology, the composition of the infusion medium and the timeliness of its use. Equally important is the assessment of the result of the infusion therapy.

The main purpose of the infusion is to maintain or restore circulating blood volume (BCC), which allows for optimal oxygen delivery (DO2) through tissue perfusion and oxygenation. In recent years, there has been a gradual paradigm shift in approaches to perioperative fluid therapy. A sufficient amount of evidence has accumulated in favor of the use of "restrictive" fluid therapy regimens for major surgical interventions. So, for example, the expediency of compensating for liquid losses in connection with its supposed transition to the "third space" has been revised. This process could not be verified reliably, and therefore no additional infusion load is required ${ }^{[1]}$. Based on the results of a number of relevant studies, it can be argued that the strategy of zero balance or moderate BCC deficit has a number of advantages over "liberal" infusion therapy regimens, inevitably accompanied by volume overload [2,3]. Also, the understanding of the movement of fluid across the endothelial barrier has expanded significantly.

In accordance with modern concepts, the leading role in the regulation of the permeability of the endothelial layer for fluid with dissolved low-molecular components, the interstitium previously diverted to the colloid-osmotic pressure, belongs to the endothelial glycocalyx. 
The molecular "sieve" of the glycocalyx, consisting of glycoproteins and proteoglycans, is in constant dynamic equilibrium with circulating plasma and is a key component in regulating the balance of forward and reverse fluid filtration. This fact contributed to the revision of the traditional Starling equation and formed the basis of the modern concept of a double barrier ${ }^{[3,4]}$. It should be noted that the direct damaging effect on the glycocalyx followed by endothelial dysfunction is caused by atrial sodium uretic peptide released by the distended right atrium in response to volume overload. This leads to the movement of fluid into the interstitial space and the development of interstitial edema of organs and tissues ${ }^{[5]}$.

Thus, most authors reasonably consider a priority restrictive strategy of infusion therapy, based on maintaining the patient's basic fluid requirement $(1-1.5 \mathrm{ml} / \mathrm{kg} / \mathrm{h})$, taking into account persistent losses of the surgical field (0.5-1.0 $\mathrm{ml} / \mathrm{kg} / \mathrm{h}$ ). Visible fluid losses (blood loss, tube losses, drainage) are additionally replenished. Despite the simplicity and physiological nature of this approach, there remains a serious risk of hypovolemia, which is facilitated by a number of factors related both to the patient (initial state, pathophysiological features of the underlying disease, the nature of concomitant pathology, taking various drugs, including hypotensive, mechanical preparation of the gastrointestinal tract (GIT) and preoperative fasting), and with the peculiarities of anesthesia (combination of general anesthesia with regional methods) and surgical intervention (duration of the operation, surgical trauma, blood loss). At the same time, the traditional diagnosis of hypovolemia based on the data of routine monitoring of integral hemodynamic parameters is often ineffective, because arterial pressure (BP) and heart rate (HR) can remain within normal values even with a significant deficit of BCC, and the central venous pressure (CVP) parameter in most situations does not correlate with the degree of hydration ${ }^{[7}$, ${ }^{8]}$. The negative consequences of latent hypovolemia, masked by stable hemodynamics, primarily concern the organs of the splanchnic zone. For perfusion disturbance in this zone, $10-15 \%$ of the BCC deficiency is sufficient, while the situation is aggravated by selective vasoconstriction of mesenteric arteries, which is an important compensatory mechanism for maintaining systemic blood pressure in hypovolemia ${ }^{[9,11]}$.

The result can be a dysfunction of the digestive tract, ranging from oppression of peristalsis and ending with the failure of internecinal anastomoses ${ }^{[11]}$. A liberal approach to fluid therapy in this category of patients does not completely solve the problem.

At the local level of the surgically damaged intestinal wall, the fluid content in its interstitium increases, and even minimal infusion volumes can multiply this edema ${ }^{[12]}$. The consequences of hypervolemia for the gastrointestinal tract are similar to those of hypovolemia. Edema of the intestinal wall, as well as its ischemia, is the cause of impairment of the barrier function and synthesis of the gastrointestinal mucosa of various acute phase proteins, cytokines and hormones acting at the local and systemic levels, which can lead to the development of organ dysfunction and severe complications ${ }^{[13,14]}$.

The optimal solution to the problem of perioperative fluid therapy in elective abdominal surgery can be considered the concept of targeted fluid therapy based on the use of functional hemodynamic parameters. The usual parameters of invasive monitoring of hemodynamics - stroke volume (SV), cardiac output (SV), cardiac index (CI), are of limited value, because their assessment will not give an unambiguous answer to the question whether their low values are associated with a deficit $\mathrm{BCC}$, or due to the effects of anesthesia. In such situations, the empirical infusion load will be effective only in half of the patients, while the other half will not respond by increasing the work of the heart to increase the preload, which will contribute to volume overload and fluid transfer into the interstitium $[15$, 16]. Functional hemodynamic parameters of stroke volume variability (SVV) or pulse pressure (CPV) are excellent for assessing the state of the $\mathrm{BCC}$ and identifying patients responding to an increase in preload due to infusion. Under mechanical ventilation, these parameters make it possible to predict an increase in $\mathrm{CO}$ in response to an infusion load with a sensitivity and specificity of more than $80 \%$, thereby making it possible to individualize infusion therapy ${ }^{[17]}$. A weighty argument for the routine use of these parameters is that the possibility of obtaining them is realized in a number of minimally invasive hemodynamic monitoring systems, where only radial artery catheterization is required and no calibration is required. This approach greatly simplifies the process of obtaining indicators of central hemodynamics, contributing to both the wider dissemination of invasive monitoring among specialists and the expansion of indications for the use of invasive monitoring in routine surgical patients.

Purpose of the study: to assess the impact of intraoperative targeted therapy (CNT), controlled on the basis of monitoring IUO, on the postoperative results of major surgical interventions on the gastrointestinal tract.

\section{Material and Methods}

The prospective study included 80 patients. An inclusive condition was a planned surgical intervention with an expected duration of at least 3 hours on the abdominal organs with a violation of the integrity of the small or large intestine and the formation of an inter-intestinal anastomosis.

The exclusion criteria were: patient refusal to participate in the study, age less than 50 years and more than 80 years; urgent nature of the surgical intervention, pronounced concomitant pathology (above grade 3 on the ASA scale); heart rhythm disturbances; operations on the upper gastrointestinal tract (esophagus, stomach, duodenum).

The patients were randomly divided into two groups: the control group and the CNT group. In both groups, surgery was performed under conditions of combined anesthesia (endotracheal + epidural) using identical drugs to induce and maintain anesthesia. In the control group $(n=41)$, infusion therapy was performed with Ringer's solution, the base rate of infusion was $4-5 \mathrm{ml} / \mathrm{kg} / \mathrm{h}$. An increase in the rate of infusion and additional bolus administration of solutions were performed based on the data of routine monitoring of hemodynamics (blood pressure, heart rate) and the degree of blood loss, taking into account the intraoperative situation. With a decrease in mean arterial pressure (MAP) less than $60 \mathrm{~mm} \mathrm{Hg}$. Art and the lack of effect from an additional bolus of fluid $(5-10 \mathrm{ml} / \mathrm{kg}$ ), the administration of vasoactive drugs (ephedrine 0.1-0.2 $\mathrm{mg} / \mathrm{kg}$, mezaton $0.25-0.5 \mathrm{mg}$ ) was used. If hypotension could not be corrected within 20 minutes, they switched to prolonged infusion of dopamine with an initial dose of 5-10 
$\mu \mathrm{g} / \mathrm{kg} / \mathrm{min}$ or norepinephrine $0.1 \mu \mathrm{g} / \mathrm{kg} / \mathrm{min}$, followed by dose titration to maintain SBP at within $70-90 \mathrm{~mm} \mathrm{Hg}$. Art. Heart rate was maintained at a level of at least 50 beats per minute, with its decrease, atropine was used (if ineffective, prolonged dopamine infusion of $5 \mu \mathrm{g} / \mathrm{kg} / \mathrm{min}$ ). In the CNT group $(n=39)$, basic infusion therapy was carried out with Ringer's solution similarly to the control group, and additional bolus administration of solutions and the use of vasoactive drugs was performed based on the data of invasive hemodynamic monitoring (Vigileo FloTrac; Edwards Life sciences Corporation, USA). The main goal was to maintain the ESR less than $13 \%$ by means of a bolus infusion load with Ringer's solution $(3-5 \mathrm{ml} / \mathrm{kg}$ ) aimed at achieving a $\mathrm{CI}$ of at least $2 \mathrm{~L} / \mathrm{min} / \mathrm{m} 2$. When the ESR is less than $13 \%$ and the remaining SI is less than $21 / \mathrm{min} / \mathrm{m} 2$, a bolus administration of ephedrine $0.1-0.2 \mathrm{mg} / \mathrm{kg}$ or mesatone $0.25-0.5 \mathrm{mg}$ was used to maintain the latter. If these measures were ineffective, an extended infusion of dopamine with an initial dosage of $5-10 \mu \mathrm{g} / \mathrm{kg} / \mathrm{min}$ or noradrenaline of $0.1 \mu \mathrm{g} / \mathrm{kg} / \mathrm{min}$ was started within 20 minutes, followed by dose titration to maintain SBP within $70-90 \mathrm{~mm} \mathrm{Hg}$. Art., and SI more than $2.51 / \mathrm{min} / \mathrm{m} 2$. In case of VUV more than $13 \%$ and ineffectiveness of 2 attempts of bolus infusion load in combination with SI less than 2 $\mathrm{L} / \mathrm{min} / \mathrm{m} 2$, catecholamines were used according to the above-described scheme. In this case, heart rate was maintained by the methods used in the control group. The algorithm of targeted therapy during the study is shown in Fig. 1.

As a marker of tissue oxygenation, the concentration of arterial blood lactate was assessed before the start of surgery and after the main stage of the operation, which was conventionally considered the formation of an interintestinal anastomosis. During the first days after surgery, all patients were observed in the conditions of the department of anesthesiology and resuscitation (OAR). Basic infusion therapy during this period was performed with Ringer's solution at the rate of $1.5-2 \mathrm{ml} / \mathrm{kg} / \mathrm{h}$. On the next day after surgery, the degree of manifestation of organ dysfunction was recorded according to the SOFA scale. As the main clinical outcome, the incidence of complications was measured within 28 days after the operation. As secondary outcomes, the concentration of arterial blood lactate after the main stage of the operation, the degree of manifestation of organ dysfunction on the next day after the operation, the length of stay in the AR and the hospital, and the timing of restoration of gastrointestinal tract functions were assessed.

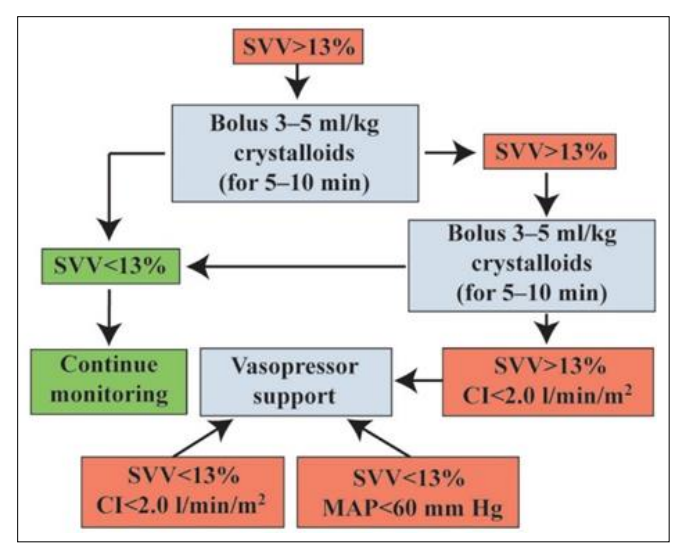

Fig 1: Protocol for intraoperative targeted infusion therapy
For the statistical analysis, the software packages Microsoft Excel 2013, StatPlus 6, IBM SPSS Statistics v.22 were used. Distribution normality was assessed using the Shapiro-Wilk test. Data are presented as arithmetic mean M \pm standard deviation $\sigma$ or median Me (25th and 75th percentiles) depending on the distribution. The significance of differences was assessed using parametric and nonparametric tests: Student's t-test or Mann-Whitney Utest. The $\chi 2$ test and Fisher's exact test were used to analyze qualitative features. A $p$-value $<0.05$ for all tests was considered statistically significant.

\section{Results and Discussion}

In both groups, the patients were comparable in terms of demographic and anthropometric parameters, laboratory parameters and manifestations of concomitant pathology. There were no significant differences between the groups in terms of the duration of surgery and the volume of blood loss. The median operation time was 280 (230-395) minutes in the CNT group and $280(225-407.5)$ minutes in the control group $(\mathrm{p}=0.936)$. Blood loss in the CNT group was $200(100-400) \mathrm{ml}$, in the control group - 150 (100-300) $\mathrm{ml}$ $(\mathrm{p}=0.48)$. The nature of the surgical interventions performed is presented.

The total volume of intraoperative infusion in the CNT group in comparison with the control group was lower both in absolute values and in terms of body weight and operation time: $2700(2000-3700) \mathrm{ml}$ versus 3400 (2500$4600) \mathrm{ml}(\mathrm{p}=0.02)$ and $6.6 \pm 0.8 \mathrm{ml} / \mathrm{kg} / \mathrm{h}$ versus $8.8 \pm 1.9$ $\mathrm{ml} / \mathrm{kg} / \mathrm{h}(p<0.001)$, respectively. The intraoperative diuresis rate did not differ between the groups: $73 \pm 20 \mathrm{ml} / \mathrm{h}$ in the CNT group and $69 \pm 31 \mathrm{ml} / \mathrm{h}$ in the control group $(\mathrm{p}=$ 0.62). In the CNT group, 26 patients (67\% of the total group size), based on monitoring the ESR, required a bolus infusion of fluid to increase the preload (based on an increase in ESR>13\%), a total of 56 cases of such observations, including repeated ones, were noted.

Only in 7 patients these episodes were accompanied by a decrease in $\mathrm{SBP}<60 \mathrm{~mm} \mathrm{Hg}$. Art., in the remaining 19 patient's episodes of hypovolemia were noted with $S B P>60$ $\mathrm{mm} \mathrm{Hg}$. Art.

Infusion therapy on the first day after surgery had no significant differences and amounted to $1.7 \pm 0.3 \mathrm{ml} / \mathrm{kg} / \mathrm{h}$ in the CNT group versus $1.6 \pm 0.3 \mathrm{ml} / \mathrm{kg} / \mathrm{h}$ in the control group $(\mathrm{p}=0.41)$.

Arterial blood sampling was performed before the surgical incision and after the main stage of the surgical intervention (formation of the inter-intestinal anastomosis). In both groups, when examining the acid-base state (CBS) of arterial blood before the start of surgery, there were no significant differences in any of the monitored parameters. At the end of the surgery, a significant intragroup decrease in $\mathrm{pH}, \mathrm{HCO}$ - and $\mathrm{BE}$ parameters was noted. In the CNT group, a significant decrease in $\mathrm{pH}$ was noted from $7.35 \pm$ 0.05 to $7.3 \pm 0.06(\mathrm{p}=0.01), \mathrm{HCO}-$ from $24.4 \pm 2.7$ to $21.5 \pm 2.3 \mathrm{mmol} / \mathrm{l}(\mathrm{p}=0.03), \mathrm{BE}$ from $-1.8 \pm 3.2$ to $-4.8(-6$ - -2.9) $\mathrm{mmol} / \mathrm{l}(p<0.001)$. In the control group, $\mathrm{pH}$ decreased from $7.36 \pm 0.06$ to $7.29 \pm 0.06(p<0.001), \mathrm{HCO}-$ from $24.5 \pm 2.4$ to $21.0 \pm 3.0 \mathrm{mmol} / \mathrm{L}(\mathrm{p}=0.011), \mathrm{BE}$ from $-1.7 \pm$ 3.1 to $-4.9(-6--2.8) \mathrm{mmol} / \mathrm{L}(\mathrm{p}=0.001)$. Also, by the end of the surgery, there was a significant increase in the potassium content in comparison with the initial values: in the CNT group from $3.6 \pm 0.4 \mathrm{mmol} / \mathrm{L}$ to $3.9 \pm 0.6 \mathrm{mmol} / \mathrm{L}$ $(p<0.001)$, in the control group from $3.8 \pm 0.3$ to $4.0 \pm 0.6$ 
$\mathrm{mmol} / \mathrm{L}(p=0.004)$. There were no significant intergroup differences in these indicators. In the control group, attention is drawn to the decrease in the $\mathrm{pO} 2 / \mathrm{FiO} 2$ ratio by the end of the operation in comparison with the initial value ( $p=0.047$ ), which turned out to be significantly lower in comparison with the CNT group: $371 \pm 92$ and $419 \pm 85$, respectively $(p=0.02)$.

Before the start of surgery, the concentration of lactate, which was used to assess the state of tissue perfusion and oxygenation, did not differ significantly between the groups: $0.9 \pm 0.2 \mathrm{mmol} / \mathrm{L}$ in the CNT group versus $0.8 \pm 0.2$ $\mathrm{mmol} / \mathrm{L}$ in the control group $(\mathrm{p}=0.11)$. After the main stage of the operation in the control group, the lactate concentration was $1.0(0.7-1.4) \mathrm{mmol} / \mathrm{L}$, which turned out to be significantly higher than in the CNT group - 0.7 (0.6-0.8) $\mathrm{mmol} / \mathrm{L}(p=0.02)$.

Average length of stay in AAR in both groups was 1 day (1 $(1-1)$ in the CNT group, $1(1-2)$ in the control group ( $p=$ $0.25)$. The number of days in the hospital after the operation also did not have significant differences; - 12 (8-15) days in the CNT group and 14 (10-17) in the control group ( $p=$ $0.14)$.

The number of patients with signs of organ dysfunction ("1 point on the SOFA scale in comparison with the preoperative assessment) on the next day after surgery in the CNT group was less than in the control group: 15 versus 25 , respectively $(p=0.04)$. In the structure of organ dysfunction, disorders of the liver and kidneys prevailed.

Restoration of gastrointestinal tract functions, in particular peristalsis, in the CNT group occurred earlier: on average, 16 hours (12-18) after surgery, while in the control group the same period was 20 hours $(18-36)(p<0.001)$. Also, in the CNT group, patients started a full meal at an earlier date: on average, on day 3 (2-4), and in the control group, on day $4(3-5)(\mathrm{p}=0.004)$.

In the CNT group, the number of patients with complications was significantly less than in the control group: 11 people (28\% of patients) versus 21 (51\% of patients), respectively $(\mathrm{p}=0.03)$. The total number of complications in the CNT group was 19, and in the control group - 40. Repeated surgery was required in 2 patients in the CNT group (1 case of intestinal anastomosis leakage, 1 case of ileoconduct failure) and 4 patients in the control group (in 2 cases - incompetence of the inter-intestinal anastomosis, in 1 case - paraileostomy abscess, in 1 case subcutaneous eventration). In addition, in 2 patients of the control group, there was an inter-intestinal anastomosis failure after rectal resection, which did not require surgical intervention (retroperitoneal sigmoctal anastomosis). Complications from the gastrointestinal tract prevailed in both groups, but in the CNT group, the number of patients with this type of complications was significantly lower in comparison with the control group: 8 patients/11 complications versus 17 patients/19 complications, respectively $(p=0.04)$. The main part of complications was postoperative paresis ( 6 patients in the CNT group and 11 in the control group). Gastrointestinal bleeding (GIB) developed in 1 patient of the CNT group and 4 patients of the control group. In both groups, 1 lethal outcome was noted as a result of the progression of multiple organ failure syndrome (MDS) after intestinal anastomosis failure and peritonitis developed. The number and nature of all complications are presented. A large number of gastrointestinal complications in both groups is quite natural. First, the nature of the surgical intervention implied a direct mechanical effect on the digestive tract. Secondly, the high sensitivity of the gastrointestinal mucosa to ischemia and the weak correlation of routine hemodynamic parameters with the volume of the BCC led to situations when the organs of the splanchnic zone underwent hypoperfusion and ischemia against the background of stable routine hemodynamic parameters (SBP>60 mm Hg). The number of such "Hidden" episodes of hypovolemia in the CNT group amounted to 45 cases in 19 patients. Thanks to their prompt identification by means of monitoring the ESO, they were promptly corrected by the infusion load. Obviously, in the control group, similar episodes also occurred, but were not verified due to the lack of specific monitoring, and the impairments of splanchnic perfusion arising against this background could serve as one of the most probable reasons for the increase in the number of complications from the digestive tract. This hypothesis is confirmed by the structure of organ dysfunction (SOFA scale) on the next day after surgery: liver dysfunctions prevailed in the control group. The reason for the high frequency of renal dysfunction in the structure of organ dysfunction in both groups ( 9 patients in the CNT group and 11 in the control group), we believe, is the use of unbalanced solutions.

In general, the decrease in the total number of complications and the lower incidence of organ dysfunction in the CNT group can be explained in a similar way for the gastrointestinal tract. An indirect confirmation of more adequate tissue perfusion and oxygenation in the CNT group is the comparatively lower arterial blood lactate content at the end of the operation in the patients of this group in comparison with the control group.

We should also pay special attention to the function of the lungs by the end of the surgery. Despite the relatively small difference in the total infusion volumes $(700 \mathrm{ml}$ or 2.2 $\mathrm{ml} / \mathrm{kg} / \mathrm{h}$ ), this was sufficient for a significant decrease in the pO2/FiO2 ratio in the control group, which indicates a high sensitivity of the lung tissue to excessive infusion load. Despite the minimal number of complications from the respiratory system in the framework of this study, this feature may be of decisive importance in certain situations ${ }^{[18]}$. Assessment of the severity of postoperative

\section{Conclusion}

The results of the study allow us to conclude that targeted infusion therapy, based on the monitoring of IUO as a key parameter, allows optimizing the infusion load, which contributes to a decrease in the number of patients with complications and an earlier recovery of gastrointestinal tract functions after major surgical procedures. Interventions on the digestive tract.

\section{References}

1. Brandstrup B, Svensen C, Engquist A. Hemorrhage and operation cause a contraction of the extracellular space needing replacement- evidence and implications? A systematic review. Surgery 2006;139(3):419-432. DOI: 10.1016/j.surg.2005.07.035. PMID: 16546507

2. Brandstrup B, Svendsen PE, Rasmussen M, Belhage B, Rodt SA, Han-sen B et al. Which goal for fluid therapy during colorectal surgery is followed by the best outcome: near-maximal stroke volume or zero fluid 
balance? Br J Anaesth 2012;109(2):191-199. DOI: 10.1093/bja/aes163. PMID: 22710266

3. Navarro LH, Bloomstone JA, Auler JO, Cannesson M, Rocca GD, Gan TJ et al. Perioperative fluid therapy: a statement from the international Fluid Optimization Group. Perioper Med (Lond) 2015;4:3.

DOI: 10.1186/s13741-015-0014-z. PMID: 25897397

4. Rehm M, Bruegger D, Christ F, Conzen P, Thiel M, Jacob $\mathrm{M}$ et al. Shed-ding of the endothelial glycocalyx in patients undergoing major vascular surgery with global and regional ischemia. Circulation 2007;116 (17):1896-1906.

DOI: $\quad$ 10.1161/CIRCULATIONAHA.106.684852. PMID: 17923576

5. Woodcock TE, Woodcock TM. Revised Starling equation and the glyco-calyx model of transvascular fluid exchange: an improved paradigm for prescribing intravenous fluid therapy. Br J Anaesth 2012;108(3): 384-394. DOI: 10.1093/bja/aer515. PMID: 22290457

6. Bruegger D, Jacob M, Rehm M, Loetsch M, Welsch U, Conzen $\mathrm{P}$ et al. Atrial natriuretic peptide induces shedding of endothelial glycocalyx in coronary vascular bed of guinea pig hearts. Am J Physiol Heart Circ Physiol 2005;289(5):H1993-H1999.

DOI: 10.1152/ajpheart.00218.2005. PMID: 15964925

7. Kozek-Langenecker SA, Ahmed AB, Afshari A, Albaladejo P, Aldecoa C, Barauskas G et al. Management of severe perioperative bleeding: guidelines from the European Society of Anaesthesiology: first update 2016. Eur J Anaesthesiol 2017;34(6):332-395.

DOI: $\quad 10.1097 / E J A .0000000000000630 . \quad$ PMID: 28459785

8. Marik PE, Cavallazzi R. Does the central venous pressure predict fluid responsiveness? An updated meta-analysis and a plea for some common sense. Crit Care Med 2013;41(7):1774-1781.

DOI: $\quad 10.1097 / C C M .0 b 013 e 31828 a 25 f d . \quad$ PMID: 23774337

9. Takala J. Determinants of splanchnic blood flow. Br J Anaesth 1996;77(1):50-58. DOI: 10.1093/bja/77.1.50. PMID: 8703630

10. Hamilton-Davies C, Mythen MG, Salmon JB, Jacobson D, Shukla A, Webb AR. Comparison of commonly used clinical indicators of hypovo-laemia with gastrointestinal tonometry. Intensive Care Med 1997; 23(3):276-281. DOI: 10.1007/s001340050328. PMID: 9083229

11. Kusano C, Baba M, Takao S, Sane S, Shimada M, Shirao K, Natsugoe S, Fukumoto T, Aikou T. Oxygen delivery as a factor in the development of fatal postoperative complications after oesophagectomy. Br J Surg 1997;84(2):252-257.

DOI: 10.1002/bjs.1800840232. PMID: 9052449

12. Chan ST, Kapadia CR, Johnson AW, Radcliffe AG, Dudley HA. Extra-cellular fluid volume expansion and third space sequestration at the site of small bowel anastomoses. Br J Surg 1983;70(1):36-39. PMID: 6824880

13. Swank GM, Deitch EA. Role of the gut in multiple organ failure: bacterial translocation and permeability changes. World J Surg 1996;20(4):411-417.

DOI: $10.1007 / \mathrm{s} 002689900065$. PMID: 8662128
14. Souza DG, Lomez ES, Pinho V, Pesquero JB, Bader M, Pesquero JL et al. Role of bradykinin B2 and B1 receptors in the local, remote, and systemic inflammatory responses that follow intestinal ische mia and reperfusion injury. J Immunol 2004;172(4):25422548.

DOI: 10.4049/jimmunol.172.4.2542. PMID: 14764727

15. Michard F, Teboul JL. Respiratory changes in arterial pressure in mechanically ventilated patients. In: Vincent JL. (ed.). Yearbook of Intensive Care and Emergency Medicine 2000. Berlin-Heidelberg: Springer 2000, P696-704. ISBN 978-3-540-66830-5

16. Svensén $\mathrm{CH}$, Olsson J, Hahn RG. Intravascular fluid administration and hemodynamic performance during open abdominal surgery. Anesth Analg 2006;103(3):671-676.

DOI: 10.1213/01.ane.0000226092.48770.fe. PMID: 16931679

17. Marik PE, Cavallazzi R, Vasu T, Hirani A. Dynamic changes in arterial waveform derived variables and fluid responsiveness in mechanically ventilated patients: a systematic review of the literature. Crit Care Med 2009;37(9):2642-2647.

DOI: 10.1097/CCM.0b013e3181a590da. PMID: 19602972

18. Arslantas MK, Kara HV, Tuncer BB, Yildizeli B, Yuksel M, Bostanci K, Bekiroglu N, Kararmaz A, Cinel I, Batirel HF. Effect of the amount of intraoperative fluid administration on postoperative pulmonary complications following anatomic lung resections. J Thorac Cardiovasc Surg 2015;149(1):314-320. DOI: 10.1016/j.jtcvs.2014.08.071. PMID: 25304302

19. Dindo D, Demartines N, Clavien PA. Classification of surgical complications: a new proposal with evaluation in a cohort of 6336 patients and results of a survey. Ann Surg 2004;240(2):205-213.

DOI: 10.1097/01.sla.0000133083.54934.ae. PMID: 15273542 